\title{
Vascular protective actions of the angiotensin receptor blockers valsartan and losartan in STZ-induced diabetic rats
}

\author{
Aliaa E. M. K. El-Mosallamy ${ }^{1 *}$, Hala F. Zaki ${ }^{2}$, Nermeen Shaffie ${ }^{3}$, Somaia A. Nada ${ }^{1}$, Amany A. Sleem ${ }^{1}$, Sanaa A. Kenawy ${ }^{2}$ \\ ${ }^{1}$ Department of Pharmacology, National Research Centre, Cairo, Egypt. \\ ${ }^{2}$ Department of Pharmacology and Toxicology, Faculty of Pharmacy, Cairo University, Cairo, Egypt. \\ ${ }^{3}$ Department of Pathology, National Research Centre, Cairo, Egypt.
}

\begin{tabular}{l}
\hline ARTICLE INFO \\
\hline Received on: 11/06/2018 \\
Accepted on: $28 / 11 / 2018$ \\
Available online: $18 / 04 / 2019$ \\
\\
\hline Key words: \\
Diabetes, angiotensin, \\
hypertension, oxidative stress, \\
angiotensin receptor blockers.
\end{tabular}

\section{INTRODUCTION}

Diabetes is a public health problem in both developing and developed countries. Globally, based on the seventh edition of the International Diabetes Federation (IDF) atlas, there were more than 415 million adults diagnosed with diabetes in 2015. This number is projected to increase to 642 million people worldwide by 2040, with type 2 diabetes mellitus (T2DM) accounting for

\section{${ }^{*}$ Corresponding Author}

Aliaa E. M. K. El-Mosallamy, Department of Pharmacology, National Research Centre, Cairo,Egypt.E-mail: aliaamoneer@hotmail.com

\begin{abstract}
Augmentation of angiotensin II (Ang II) signaling with the subsequent overproduction of the reactive oxygen species (ROS) has been documented to be involved in the development of diabetic cardiovascular complications. This study aimed to assess the potential impact of angiotensin II type 1 (AT1) receptors blockage, with valsartan or losartan, on the progression of the cardiovascular complications associated with diabetes in comparison with the classical antidiabetic drug, metformin. Animals were randomly assigned to one normal group, one group of untreated streptozotocin (STZ) (45 mg/kg)-induced type I diabetic rats, and five groups of STZ diabetic rats that received different daily oral treatments over a 6-week period as follows: metformin $(100 \mathrm{mg} / \mathrm{kg})$, valsartan (7 and $14 \mathrm{mg} / \mathrm{kg})$, and losartan (5 and $10 \mathrm{mg} / \mathrm{kg})$. Systolic blood pressure and heart rate were measured weekly. At the end of the study, blood samples were withdrawn for the estimation of the oxidative stress biomarkers, and histopathological assessments of aorta were conducted as well. The STZ-induced diabetic rats exhibited blood pressure elevation, heart rate reductions, disturbances in the oxidative stress biomarkers, as well as aortic histopathological aberration compared with normal control group. Metformin administration resulted in a non-significant tendency to ameliorate the elevated blood pressure with no effect on the heart rate and partially reversed the disrupted oxidative stress biomarkers. However, treatment with valsartan or losartan abolished the development of hypertension in diabetic rats with no effect on the associated bradycardia and successfully attenuated the generation of ROS as compared to the diabetic rats. Treatment with metformin, valsartan, and losartan showed ameliorative effects on the aortic histopathological aberrations observed in diabetic rats. In STZ diabetic rats, our data suggest that the beneficial effects afforded by blockage of the AT1 receptor with valsartan or losartan treatments could be in part mediated through a mechanism that may involve inhibition of ROS production.
\end{abstract}


Diabetes is known to markedly raise morbidity and mortality rates due to the progressive development of cardiovascular complications. It is associated with a greater incidence of hypertension and atherosclerosis which are considered major risk factors in the development of diabetic cardiomyopathy and stroke (Fiorino et al., 2012; Sasaki et al., 2013).

A strong crosstalk between oxidative stress and hyperglycemia has been documented; oxidative stress is a major contributor in pathogenesis and progression of diabetes and its related cardiovascular complications. On the other hand, hyperglycemia has been proposed to play a pivotal role in inducing the generation of the reactive oxygen species (ROS) in both types of diabetes (Mihailovic et al., 2015).

Hyperglycemia has been shown to increase the incidence of hypertension in humans and in animal models of diabetes. This increase in blood pressure has been attributed to the over activation of the renin-angiotensin system (RAS) with a subsequent production of the vasoconstrictor angiotensin II (Ang II) (Fang et al., 2004; Malfitano et al., 2012). There is a growing body of evidence that the dysregulation of the RAS is a strong promoter for the formation of ROS (Senapaty et al., 2014). In addition, several studies have postulated that Ang II is closely involved in the progression of arterial stiffness, enhancing vascular smooth muscle cell proliferation, and the formation of atherosclerotic plaques independent of its actions on blood pressure (Tikellis et al., 2013; Uehara and Takeda, 2008).

The objective of the present study is to investigate the potential antioxidant and vascular protective actions of long-term treatment with angiotensin receptor blockers (ARBs), namely, losartan and valsartan in streptozotocin (STZ)-induced diabetic rats.

\section{MATERIALS AND METHODS}

\section{Chemicals}

Valsartan and losartan were obtained as gifts from Novartis Pharma and Hikma Pharmaceuticals Co, Cairo, Egypt, respectively. Metformin was obtained as a gift from Amoun Pharmaceuticals Co., Cairo, Egypt and STZ was purchased from Sigma-Aldrich (MO, USA). The chemicals and reagents used in the present study were of analytical grade.

\section{Animals}

Male albino Wistar rats (240-270 g) obtained from the animal house, National Research Centre (Cairo, Egypt), were used. The animals were housed in plastic cages covered with wood shavings flooring and they were kept for at least 1 week in the laboratory room prior to testing under standard housing conditions (room temperature $25^{\circ} \mathrm{C}$ with alternating 12 hours light and dark cycles) and were allowed free access to water and food ad libitum, unless otherwise specified. All animals' procedures were performed in accordance to the Institutional Ethics Committee of Faculty of Pharmacy, Cairo University and of the National Research Centre, Egypt and in accordance with the recommendations for the proper care and use of laboratory animals.

\section{Induction of diabetes}

Overnight fasting animals were rendered diabetic by a single intraperitoneal (i.p.) injection of $45 \mathrm{mg} / \mathrm{kg} \mathrm{STZ}$ freshly dissolved in freshly prepared $0.1 \mathrm{M}$ citrate buffer $(\mathrm{pH} 4.5)$
(Lo Giudice et al., 2002). Age-matched control rats were injected with an equal volume of citrate buffer only and served as normal control. For the next 24 hours after STZ injection, the STZ treated animals were supplemented with $5 \%$ glucose solution in the drinking bottle ad libitum to counteract the initial hypoglycemia and promote survival by avoiding death due to hypoglycemic shock (Chahlia, 2009). Confirmations of the animals' diabetic state were assessed by blood glucose concentrations analysis 72 hours after STZ injection. Animals with a blood glucose level of $250 \mathrm{mg} / \mathrm{dl} \approx 14 \mathrm{mmol} / \mathrm{l}$ or higher (Hansen et al., 2007), as well as with the symptoms of polyuria, polydipsia, and polyphagia were considered diabetic, while animals not meeting these criteria were excluded from this study.

\section{Experimental design}

The selected diabetic rats were randomly assigned to six groups in addition to a seventh group (normal control). Each group consisted of 8-10 rats that received oral daily treatments for 6 weeks as follows: Group (i) received only the vehicle i.p. and served as normal rats. Group (ii) received single STZ (45 mg/kg) i.p. and served as a +ve control diabetic rats. Group (iii) diabetic rats received metformin $(100 \mathrm{mg} / \mathrm{kg} /$ day $)$ orally and served as reference standard (El-Batran et al., 2006). Group (iv) diabetic rats received valsartan (7 mg/kg/day) orally (El-Shenawy et al., 2004). Group (v) diabetic rats received valsartan (14 mg/kg/day) orally (Zhang et al., 2008). Group (vi) diabetic rats received losartan (5 mg/kg/day) orally (Mori et al., 2002). Group (vii) diabetic rats received losartan $(10 \mathrm{mg} / \mathrm{kg} /$ day) orally (Yavuz et al., 2003).

To avoid the incidence of the lethal ketoacidosis, all diabetic rats received 2 I.U. insulin (Insulatard, Novo Nordisk) daily to maintain a blood glucose level at 300-350 mg/dl (Hansen et al., 2007; Riser et al., 2003).

\section{Systolic blood pressure and heart rate measurements}

Systolic blood pressure (SBP) and heart rate of all animals were indirectly measured weekly from the tail of pretrained conscious rats by the tail cuff technique as described earlier by Fregly, (1961) and El-Mosallamy et al., (2012). This was performed using the non-invasive blood pressure monitor (model ML 125 NIBP, ADinstruments Pty. Ltd., Sydney, Australia). Training was conducted by the method described by Irvine et al. (1997). SBP (cuff deflation pressure) was defined as the point at which the cuff pressure corresponds to the restoration of the first caudal artery pulse. The average of at least three measurements was taken at each occasion. Heart rate was recorded automatically by a counter triggered by the pulse wave.

\section{Sample preparation}

Twenty-four hours after the last treatment, blood samples were withdrawn from the overnight fasted rats via the retro-orbital vein of each animal under light ether anesthesia (Cocchetto and Bjornsson, 1983) and collected in heparinized tubes. An aliquot of heparinized blood was used for estimating its reduced glutathione (GSH) level. The other aliquot was centrifuged to separate plasma, which was then used for estimation of lipid peroxides level measured as malondialdehyde (MDA).

The animals were then euthanized by decapitation. The aorta was dissected, carefully cleaned of adhering tissues, washed 
in saline, and then immediately immersed in $10 \%$ neutral buffered formalin for histopathological examination.

\section{Determination of plasma lipid peroxides}

Lipid peroxides were estimated in plasma as thiobarbituric acid reactive substances measured as MDA following the method of Mihara and Uchiyama (1978). The concentration of MDA in plasma was expressed as nanomoles per milliliter.

\section{Determination of blood reduced glutathione}

Blood GSH was determined according to the method described by Beutler et al. (1963). Briefly, this was conducted by spectrophotometric estimation of the yellow color of 5- thio-2-nitrobenzoic acid at $412 \mathrm{~nm}$. This color is produced from the reaction between GSH with 5, 5-dithiobis-(2-nitrobenzoic acid) (Ellman's reagent, DTNB). The results of blood GSH were expressed as milligrams per deciliter.

\section{Histopathological examination}

For histopathological investigation, aortic specimens from all animals were dissected immediately after decapitation, washed thoroughly with formal saline, and then fixed in $10 \%$ neutral-buffered formal saline for at least 72 hours. All the specimens were washed in tap water for half an hour, dehydrated in ascending grades of alcohol $(70 \%-80 \%-90 \%$ and finally in absolute alcohol), cleared in xylene, impregnated in soft paraffin wax at $55^{\circ} \mathrm{C}$, and then embedded in hard paraffin. Serial sections, each $6 \mu \mathrm{m}$ thick, were cut and stained with hematoxylin and eosin (Drury and Wallington, 1980). The sections were scanned and analyzed by an expert pathologist. Images were captured and processed using Adobe Photoshop version 8.0.

\section{Statistical analysis}

In the present study, all results were expressed as mean \pm standard error of the mean. All data were subjected to statistical analysis using Statgraphics Centurion XVI version 16.1.11, Stat point, Inc.

Data of SBP and heart rate were analyzed using repeated measures two-way analysis of variance (ANOVA) to test for interaction between time and grouping factors followed by Duncan's multiple range test. Results of blood GSH and lipid peroxidation were statistically analyzed using one-way ANOVA followed by Duncan's multiple range test. A probability of less than 0.05 was used as criterion for statistical significance.

\section{RESULTS}

\section{Effects of valsartan and losartan on systolic blood pressure}

The mean SBP was $107.4 \pm 3.5 \mathrm{mmHg}$ in the normal group, which did not change throughout the experimental period. Diabetes was induced with a single i.p. injection of STZ (45 mg/ $\mathrm{kg}$ ), and the diabetic untreated rats started to show a significant elevation in the SBP by $9.6 \%$ during the second week. Starting from the fourth week, the STZ diabetic untreated rats showed a significant sustained increase in the SBP until the end of the experiment by $7.34 \%, 8.77 \%$, and $15.55 \%$, respectively, as compared to that of the zero time. Additionally, administration of metformin (100 mg/kg/day) showed a milder significant increase in SBP at the end of experiment by $6.89 \%$ compared to their zero time readings.

On the other hand, the daily administration of valsartan (7 and $14 \mathrm{mg} / \mathrm{kg}$ ) and losartan (5 and $10 \mathrm{mg} / \mathrm{kg}$ ) significantly protected the STZ-induced diabetic rats from the expected elevation in the SBP (Fig. 1).

\section{Effects of valsartan and losartan on heart rate}

The mean heart rate was $308.53 \pm 11.57$ BPM in the normal group which did not change throughout the experimental period. The heart rate was significantly decreased in the diabetic untreated rats starting from the first week by $10.48 \%, 13.09 \%$, $13.68 \%, 5.27 \%, 1.74 \%$, and $5.14 \%$, respectively, to the end of the experimental period, as compared to their zero time values.

The daily administration of metformin (100 mg/ $\mathrm{kg}$ ), valsartan (7 and $14 \mathrm{mg} / \mathrm{kg}$ ), and losartan (5 and $10 \mathrm{mg} / \mathrm{kg}$ ) failed to ameliorate the decrease in heart rate observed in the STZ diabetic rats. Additionally, the heart rate lowering effect of valsartan $(7 \mathrm{mg} / \mathrm{kg})$ and losartan $(10 \mathrm{mg} / \mathrm{kg})$ was found to be significant when compared with the metformin treated group (Fig. 2).

\section{Effect of valsartan and losartan on plasma MDA and blood GSH levels}

Induction of diabetes in rats by the single intrapretoneal injection of STZ significantly increased the level of plasma MDA by $146.11 \%$ and significantly decreased the blood GSH level by $21.89 \%$ when compared with the normal rats.

The daily administration of metformin (100 mg/ $\mathrm{kg}$ ), valsartan (7 and $14 \mathrm{mg} / \mathrm{kg}$ ), and losartan (5 and $10 \mathrm{mg} /$ $\mathrm{kg}$ ) significantly decreased the plasma MDA level by $47.38 \%$, $33.53 \%, 33.27 \%, 37.19 \%$, and $29.62 \%$, respectively, as compared with the diabetic group.

Moreover, the daily administration of metformin (100 mg/kg), valsartan (7 mg/kg), and losartan (5 mg $/ \mathrm{kg})$ for 6 weeks resulted in numerical non-significant increase in blood GSH level by $13.57 \%, 11.99 \%$, and $16.63 \%$, respectively, in comparison with the diabetic rats. These results were also non-significant from the normal control rats reaching $88.71 \%, 87.48 \%$, and $91.10 \%$ of the normal control rats' value.

However, administration of valsartan $(14 \mathrm{mg} / \mathrm{kg})$ and losartan $(10 \mathrm{mg} / \mathrm{kg})$ resulted in a significant increase in the blood GSH level by $32.44 \%$ and $27.5 \%$, respectively, as compared to the STZ diabetic rats (Figs. 3 and 4).

Effects of valsartan and losartan in comparison with metformin on rat aortic pathological changes

Light microscopic examination of aortic sections obtained from normal rats showed normal appearance of the aortic structure, with intact tunica intima composed of one layer of intact endothelium, thick tunica media occupying most of the thickness of the vessel wall and appeared full of wavy elastic fibers embedded in it, and thin outer tunica adventitia made from loose connective tissue (Fig. 5).

The aortic sections of control diabetic rats showed abnormal tunica media/adventitia ratio because of thinning of the tunica media with stretching of the elastic fibers in it with noticeable increase in thickness of adventitia (Fig. 6a). 

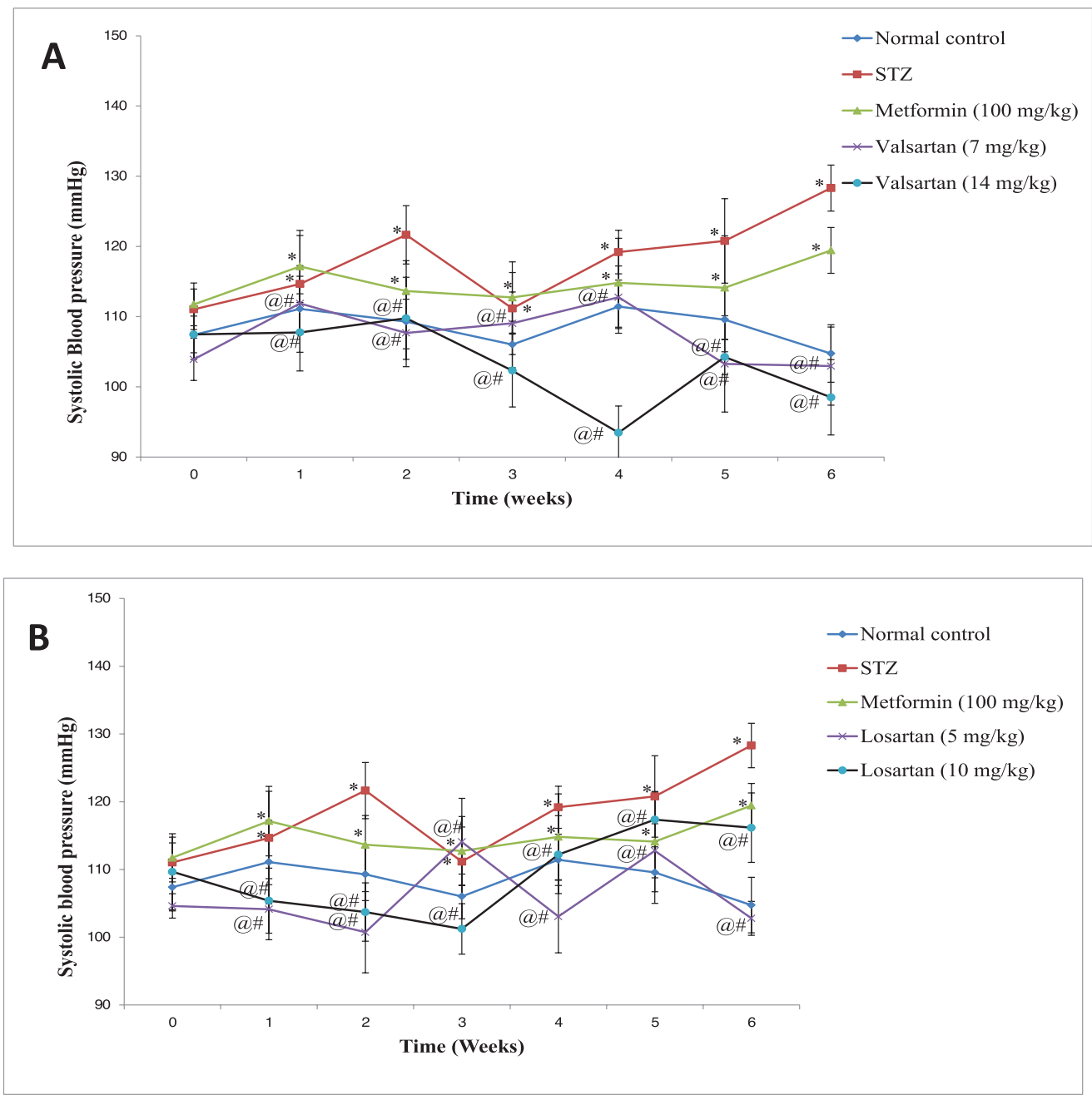

Fig. 1. Effects of (A) Valsartan (7 and $14 \mathrm{mg} / \mathrm{kg}$, P.O.) and (B) Losartan (5 and $10 \mathrm{mg} / \mathrm{kg}$, P.O.) in comparison with metformin $(100 \mathrm{mg} / \mathrm{kg}$, P.O.) on SBP in STZ-induced diabetes in rats. Diabetes was induced in rats by single intraperitoneal injection of STZ. Valsartan, losartan, and metformin were orally administered daily for 6 weeks. SBP $(\mathrm{mmHg})$ of animals was indirectly measured each week by the tail-cuff technique. Data are expressed as mean \pm SEM $(n=6-10)$. The statistical comparison of difference between groups was carried out using two-way ANOVA, followed by Duncan's multiple range test. *Statistically significant from normal control group at the corresponding time at $p<$ 0.05 . ${ }^{\circledR}$ Statistically significant from STZ control group at the corresponding time at $p<0.05$. ${ }^{\text {\#Statistically significant }}$ from metformin-treated group at the corresponding time at $p<0.05$.

Administration of metformin $(100 \mathrm{mg} / \mathrm{kg})$ daily for 6 weeks slightly modulated the STZ-induced aortic changes by the regaining of the wavy elastic fibers in tunica media. However, the adventitia is still thicker than normal (Fig. 6b).

The aortic sections of the diabetic rats that received valsartan $(7 \mathrm{mg} / \mathrm{kg})$ daily for 6 weeks showed thick adventitia and abnormal-shaped muscle fibers of tunica media with swollen disoriented nuclei, and the elastic fibers regained their wavy appearance (Fig. 6c).

The aortic sections of the diabetic rats that received valsartan $(14 \mathrm{mg} / \mathrm{kg})$ daily for 6 weeks showed normalization of the general architecture of the aortic wall although some nuclei of smooth muscle fibers of tunica media were still swollen with abnormal appearance and orientation (Fig. 6d).

Administration of losartan $(5 \mathrm{mg} / \mathrm{kg})$ daily for 6 weeks to the diabetic rats failed to ameliorate the hyperglycemic effects of STZ. The tunica media appeared thinner than normal with interlocking elastic fibers, and the elastic fibers lost their wavy appearance. In addition, the nuclei of smooth muscle fibers appeared swollen and disoriented (Fig. 6e).

On the other hand, aortic tissues of diabetic rats that received losartan $(10 \mathrm{mg} / \mathrm{kg})$ daily showed regaining of the normal architecture of the aorta (Fig. 6f).

\section{DISCUSSION}

In the present experiments, the single i.p. injection of rats with $45 \mathrm{mg} / \mathrm{kg}$ STZ elicited a time-dependent significant elevation of SBP that was associated with a significant decrease in heart rate when compared with the normal rats during the 6 weeks after the induction of diabetes.

These results were in agreement with the studies of Haidara et al. (2009) and Hussien (2014). They demonstrated 

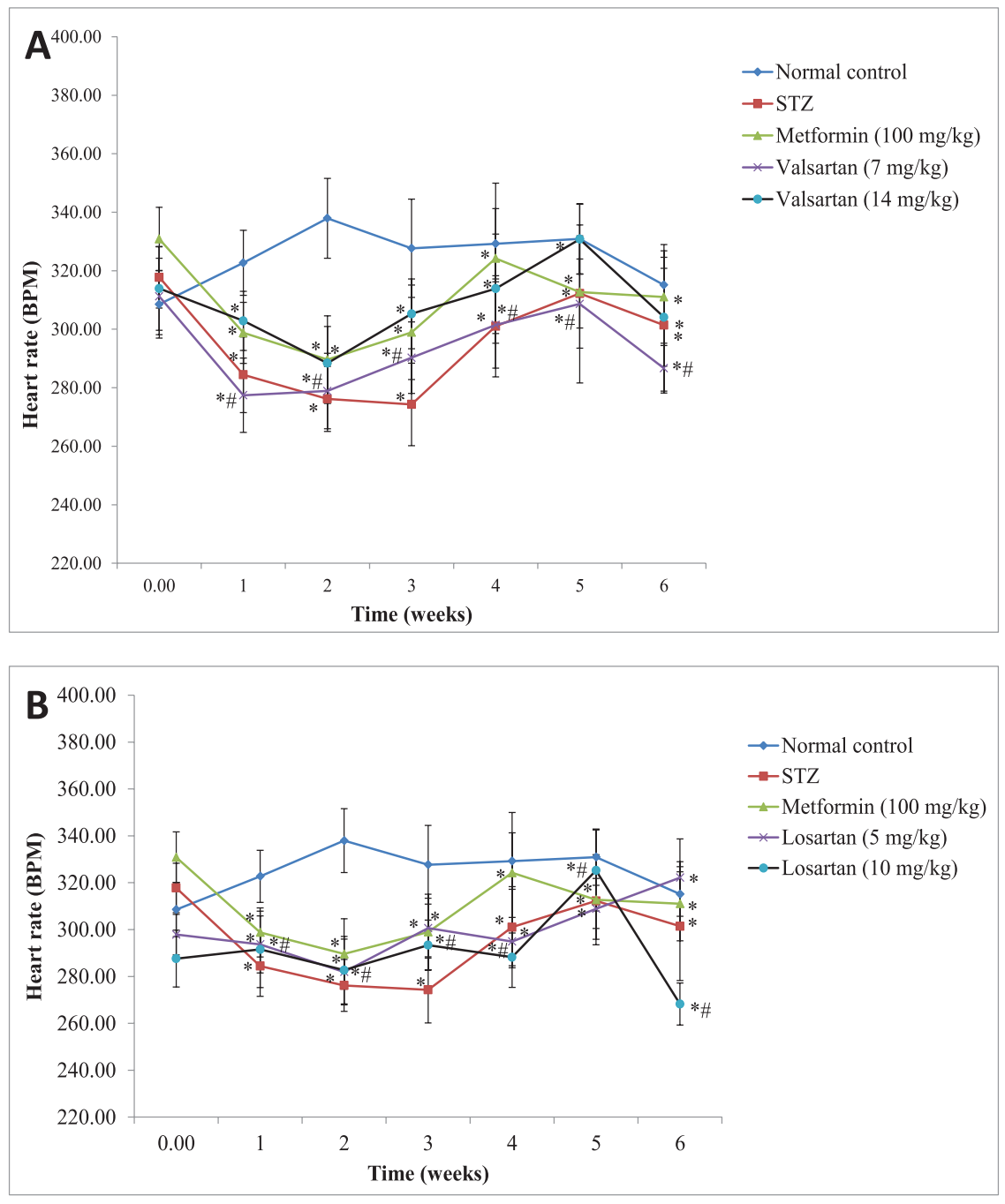

Fig. 2. Effects of (A) Valsartan (7 and $14 \mathrm{mg} / \mathrm{kg}$, P.O.) and (B) Losartan (5 and $10 \mathrm{mg} / \mathrm{kg}$, P.O.) in comparison with metformin $(100 \mathrm{mg} / \mathrm{kg}$, P.O.) on heart rate in STZ-induced diabetes in rats. Diabetes was induced in rats by single intraperitoneal injection of STZ. Valsartan, losartan, and metformin were orally administered daily for 6 weeks. Heart rate (BPM) of animals was indirectly measured each week by the tail-cuff technique. Data are expressed as mean \pm SEM $(n=6-10)$. The statistical comparison of difference between groups was carried out using two-way ANOVA, followed by Duncan's multiple range test. *Statistically significant from normal control group at the corresponding time at $p<0.05$. ${ }^{\circledR}$ Statistically significant from STZ control group at the corresponding time at $p<0.05$. "Statistically significant from metformin treated group at the corresponding time at $p<0.05$.

that induction of hyperglycemia by STZ produced marked and sustained hypertension and decreases in heart rate of the experimental rats.

Several mechanisms have been postulated to illustrate the major causative factors involved in the development of hypertension in response to hyperglycemia, including generation of ROS, inflammation, activation of sympathetic nervous system, up-regulation of rennin angiotensin aldosterone system (RAAS), accumulation of advanced glycation end-products (AGEs), as well as impaired arterial vascular integrity with subsequent atherosclerosis, arterial stiffening, and stenosis (Hussien, 2014).

The upregulation of the RAAS with the subsequent increase in the formation of Ang II is one of the major contributing mechanisms involved in the pathogenesis of hypertension under diabetic conditions. Musial et al. (2013) reported an increase in the plasma angiotensin-converting enzyme (ACE) activity in diabetic rats, suggesting augmentation of Ang II synthesis.

Angiotensin II, a potent vasoconstrictor, has emerged as a major mediator of several pathophysiological mechanisms in a number of clinical disorders such as essential hypertension, atherosclerosis, as well as in diabetic cardiovascular damage (Nasser et al., 2014). It is a well-known mitogen involved in vascular smooth muscle cell proliferation, a major causative factor for the accumulation of AGEs (Kurtz and Pravenec, 2008; Wang et al., 2013), and it has been identified as a stimulator for the progression of arterial stiffness (Uehara and Takeda, 2008). The vast majority of the cardiovascular activities of Ang II were attributed to its binding with AT1 receptors, which are widely expressed in the vasculature, heart, kidney, adrenal gland, brain, and liver (Prabhakar, 2013). 




Fig. 3. Effects of valsartan (7 and $14 \mathrm{mg} / \mathrm{kg}$, P.O.) and losartan (5 and $10 \mathrm{mg} / \mathrm{kg}$, P.O.) in comparison with metformin (100 mg/ $\mathrm{kg} /$ day, P.O.) on plasma MDA in STZ-induced diabetes in rats. Diabetes was induced in rats by single intraperitoneal injection of STZ. Valsartan, losartan, and metformin were orally administered daily for 6 weeks. Data are expressed as mean \pm SEM $(n$ $=6-8$ ). The statistical comparison of difference between groups was carried out using one-way ANOVA, followed by Duncan's multiple range test. *Statistically significant from normal control group at the corresponding time at $p<0.05$. ${ }^{\circledR}$ Statistically significant from STZ control group at the corresponding time at $p<0.05$.

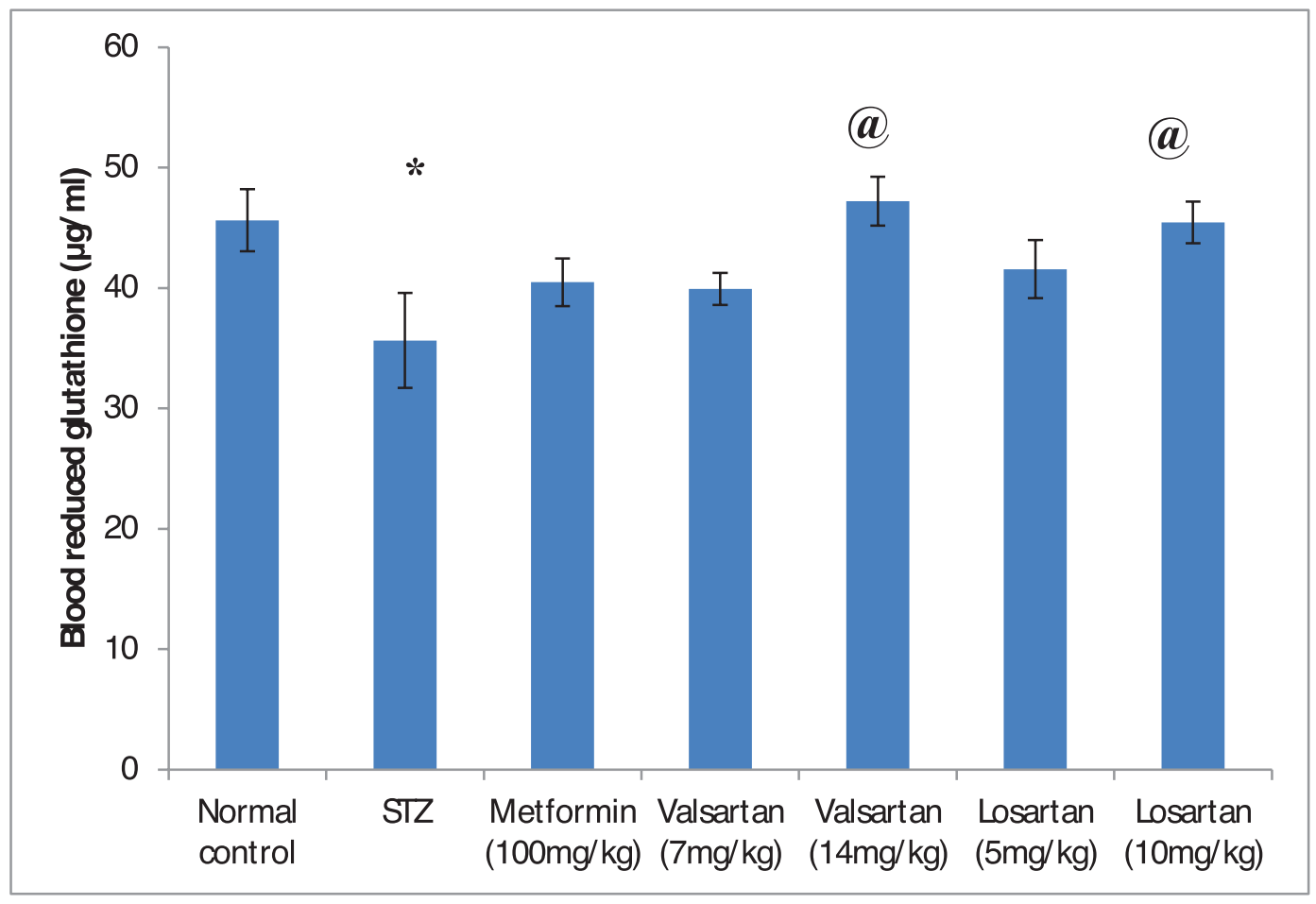

Fig. 4. Effects of valsartan (7 and $14 \mathrm{mg} / \mathrm{kg}$, P.O.) and losartan $(5$ and $10 \mathrm{mg} / \mathrm{kg}$, P.O.) in comparison with metformin (100 $\mathrm{mg} / \mathrm{kg} /$ day, P.O.) on blood reduced glutathione (GSH) in STZ-induced diabetes in rats. Diabetes was induced in rats by single intraperitoneal injection of STZ. Valsartan, losartan, and metformin were orally administered daily for 6 weeks. Data are expressed as mean $\pm \operatorname{SEM}(n=6-8)$. The statistical comparison of difference between the control group and the treated groups was carried out using one-way ANOVA, followed by Duncan's multiple range test. *Statistically significant from normal control group at the corresponding time at $p<0.05$. ${ }^{\circledR}$ Statistically significant from STZ control group at the corresponding time at $p<0.05$. 


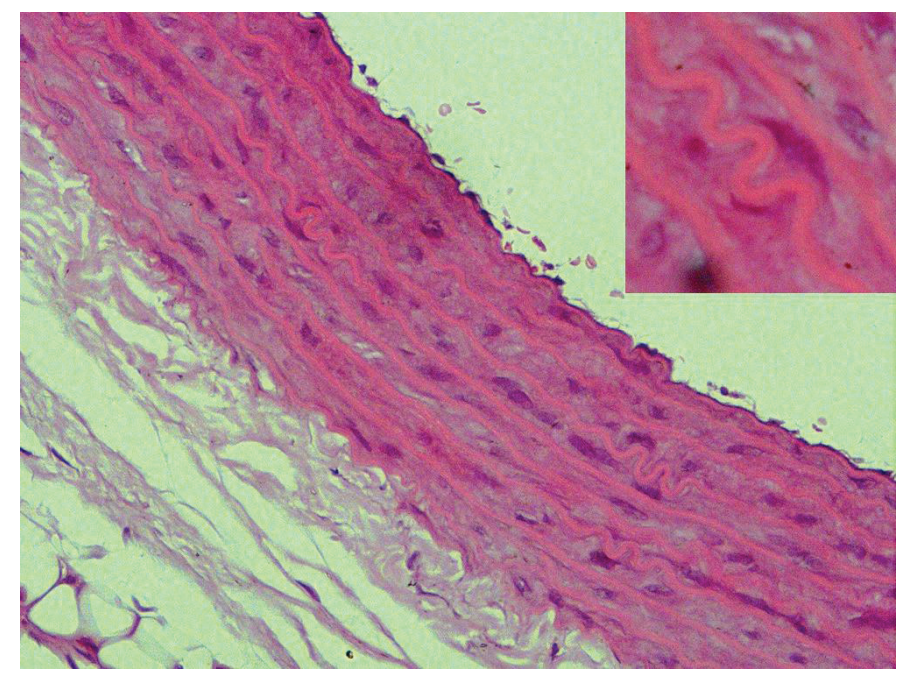

Fig. 5. A photomicrograph of an aortic section from a normal control rat showing intact tunica intima, thick tunica media occupying most of the thickness of the vessel wall with elastic fibers embedded in it and thin outer tunica adventitia made from loose connective tissue. The upper right corner of the figure shows the wavy elastic fibers characteristic of this vessel $(H \& E \times 400 \& 1,000)$.

Angiotensin II also has been shown to enhance superoxide generation through the activation of $\mathrm{NAD}(\mathrm{P}) \mathrm{H}$ oxidase independently of its systemic vasoconstriction (Fujita et al., 2011); it stimulates the expression of leukocytes adhesion molecules and the release of inflammatory cytokines (Nasser et al., 2014).

Furthermore, Kucharewicz et al. (2002) reported that Ang II could promote thrombosis through enhancing the secretion of plasminogen activator inhibitor type 1 (PAI-1) from endothelial and smooth muscle cells and increase tissue factor expression.

Additionally, the overexpression of the circulating and local levels of endothelin-1 (ET-1), as well as its abnormal signaling responses in diabetic animal models and diabetic patients has been discussed by Matsumoto et al. (2014). ET-1 is an endothelial cells (ECs)-derived peptide; it is a potent vasoconstrictor with mitogenic, pro-oxidative, and pro-inflammatory properties. The same authors also described the existing crosstalk between Ang II and ET-1. Ang II is able to enhance the expression of preproendothelin mRNA, and ET-1 in ECs, vascular smooth muscle cells (VSMCs), and vascular adventitial fibroblasts. In contrast, ET-1 was found to activate the conversion of Ang I to Ang II in pulmonary ECs. Moreover, the $\mathrm{ET}_{\mathrm{A}}$ receptor antagonism was found to reduce the vasoconstrictor responses to Ang II.

Our results revealed that the induction of diabetes by the single i.p. injection of STZ resulted in a significant decrease in GSH level, as well as a significant elevation in plasma MDA level, suggesting increased generation of ROS, and these results were in agreement with other investigators (Sabry et al., 2014; Singh et al., 2016; Soon and Tan, 2002).

Excessive oxidative stress is a well-known pathogenic mechanism of diabetes and its micro- and macro-vascular complications. It arises from an imbalance between generation and elimination of ROS (Islam and Loots, 2007; Orhan et al., 2011; Wang et al., 2013). The increase in ROS generation has

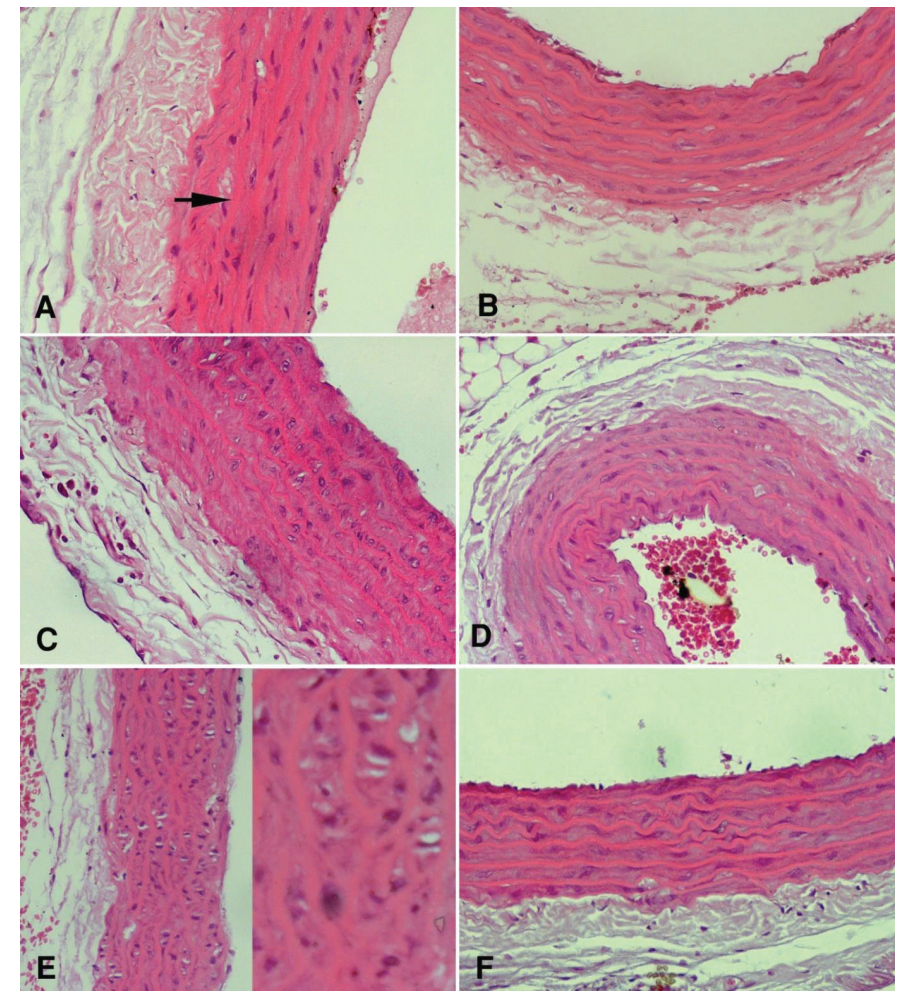

Fig. 6. A photomicrograph of aortic sections from: (A) Diabetic control rat showing thinning of the tunica media with stretching of the elastic fibers in it (arrow) with noticeable increase in thickness of adventitia. (B) Diabetic rat that received metformin $100 \mathrm{mg} / \mathrm{kg} /$ day showing regaining of the wavy elastic fibers in tunica media; however, the adventitia is still thicker than normal. (C) Diabetic rat that received valsartan $7 \mathrm{mg} / \mathrm{kg}$ /day showing wavy elastic fibers, thick adventitia, and abnormal-shaped muscle fibers of tunica media with swollen disoriented nuclei. (D) Diabetic rat that received valsartan $14 \mathrm{mg} / \mathrm{kg}$ / day showing normalization of the general architecture of the aortic wall, some nuclei of smooth muscle fibers are still swollen. (E) Diabetic rat that received losartan $5 \mathrm{mg} / \mathrm{kg} /$ day, the left half of the figure shows that the tunica media appeared thinner than normal with interlocking non-wavy elastic fibers. In the right half, the nuclei of smooth muscle fibers appeared swollen and disoriented. (F) Diabetic rat that received losartan $10 \mathrm{mg} / \mathrm{kg} /$ day showing normalization of the aortic wall $(\mathrm{H} \& \mathrm{E} \times 400)$.

been documented in both types of diabetes through multiple pathways such as increased lipid peroxidation, activation of protein kinase $\mathrm{C}$ (PKC), especially the $\beta$-isoform, activation of the NADPH oxidase, increased production of AGEs, redox imbalance secondary to enhanced aldose reductase (AR) activity, prostanoid imbalance, and mitochondrial overproduction of superoxide (Gupta et al., 2010; Kellogg, 2008).

One of the mechanisms involved in increased ROS production during hyperglycemia is the diacylglycerol (DAG) - PKC pathway. The accumulation of DAG in chronic hyperglycemia contributes in the enhancement of PKC activity leading to excessive expression and activation of NADPH oxidase in all cell types within the vascular wall, hence the oxidative stress is increased (Gupta et al., 2010).

Gupta et al. (2010) reported that the non-enzymatic glycosylation of protein leads to the formation of AGEs, and the AGEs alone and/or through its interaction with its receptor (RAGE) have the ability to further increase the oxidative stress. 
They also have been shown to potentiate the NADPH oxidase activation resulting in superoxide production, which in turn leads to increased AGEs formation, creating a cyclical pattern with positive feedback.

Additionally, Koka et al. (2006) reported the ability of AGEs to stimulate the generation of angiotensin through the activation of chymase as an alternative pathway. This could underlie the greater therapeutic benefits of using ARBs when compared with the use of ACE inhibitors.

Another link between hyperglycemia and increased generation of ROS is the activation of the polyol pathway in response to the increase in the blood glucose concentration. The metabolism of glucose by the polyol pathway has been reported to contribute in the activation of AR2 and sorbitol dehydrogenase resulting in reduction of glucose to sorbitol and fructose. Activation of this pathway leads to increased NADPH consumption which is an essential cofactor for GSH generation (Gupta et al., 2010; Thompson and Godin, 1995).

Furthermore, Gupta et al. (2010) and Musial et al. (2013) documented the ability of the increased superoxide generation to decrease nitric oxide (NO) bioavailability as a result of its chemical conversion to the potent oxidant peroxynitrite, resulting in decreased endothelial relaxation and elevated blood pressure.

The present histopathological examination of the aortic sections of diabetic rats showed several aortic alterations, including abnormal tunica media/adventitia ratio due to the thinning of the tunica media with stretching of the elastic fibers in it, and a noticeable increase in thickness of adventitia. This was in harmony with the results of Marquie et al. (1998). Patients suffering from DM are more exposed to the risk of atherothrombosis, which arises as a result of increased levels of several pro-coagulation factors (e.g., fibrinogen, factor VII, and von Willebrand factor) and a decrease in the levels of several anticoagulation factors (e.g., antithrombin III and protein C) (Ha et al., 2014).

Hyperglycemia is a leading cause for glycosylation of proteins and phospholipids to form the chemically reversible early glycosylation products which subsequently undergo a complicated series of chemical rearrangements to produce the irreversible AGEs, which have the ability to induce cross-linking of extracellular matrix proteins leading to a decrease in the compliance and stiffening of the arterial wall. This could be clinically translated into systolic hypertension (Esper et al., 2008; Gupta et al., 2010; Sampathkumar et al., 2005).

Regarding the present observed decrease in heart rate of the STZ- diabetic rats, similar results have been reported by several researchers (Goyal et al., 2009; Hassan et al., 2013; Meamar et al., 2015). The developed bradycardia was thought to be attributed to alterations in the sinoatrial (SA) node and it was found to be associated with disease progression (Sanyal et al., 2012; VanHoose, 2011).

Grise et al. (2016) reported that the STZ-treatment itself has the ability to lengthen the action potential duration in the SA node, thus slowing the heart rate; whereas, Howarth et al. (2005) documented the ability of insulin to reverse the reductions in heart rate observed in STZ-induced diabetic rats, suggesting that it is the diabetes rather than STZ treatment that is responsible for the bradycardia.

The current results demonstrated that the daily treatment of the STZ diabetic rats with valsartan ( 7 and $14 \mathrm{mg} / \mathrm{kg}$ ) and losartan
( 5 and $10 \mathrm{mg} / \mathrm{kg}$ ) for 6 weeks resulted in the normalization of SBP without any significant change on the observed bradycardia.

Regarding the antihypertensive actions, the observed blood pressure lowering effect of valsartan and losartan at both dose levels was documented by several authors (Chan et al., 2003; Hussien, 2014). Valsartan and losartan are safe and effective drugs belonging to the Angiotensin II, type 1 receptor blockers (ARBs) used for the treatment of hypertension (Hussien, 2014). Their main mechanism of action is attained through the inhibition of the Ang II signaling via blocking the AT1 receptors (Nasser et al., 2014).

The unaffected bradycardia by valsartan and losartan was in harmony with the results of Fukui et al. (2009) who showed that administration of olmesartan which is another ARB resulted in a lower heart rate in diabetic hypertensive rats compared with the normal rats. On the other hand, Hussien (2014) reported that administration of losartan in STZ diabetic rats significantly increased the heart rate to reach the normal level. This discrepancy may be attributed to the duration of hyperglycemia and to the dose of the used drugs.

It has been reported that losartan significantly abolished the increase in blood pressure and inhibited the increase in aortic ET-1 content in Ang II-induced hypertension (d'Uscio et al., 1998). Additionally, administration of losartan in a 2-weeks study, normalized diabetes-related impairments of insulin-induced relaxation in the aorta of Goto-Kakizaki (GK) type 2 diabetic rats (diabetic rats exhibiting insulin resistance and hyperinsulinemia). The effect of losartan on the insulin-induced aortic relaxation was endothelium dependent. This effect was attributed to the restoration of the NO production and eNOS phosphorylation, and the enhancement of insulin sensitivity (Nemoto et al., 2011).

The present results also revealed that administration of valsartan and losartan succeeded in ameliorating the depleted GSH, as well as the elevated level of MDA observed in the STZ diabetic rats. This was in harmony with the results of Hussien (2014) and Senapaty et al. (2014).

Zhao et al. (2007) reported that valsartan treatment significantly enhanced the superoxide dismutase (SOD) activity and suppressed the levels of hydroxyl radical $\left(\mathrm{OH}^{\circ}\right), \mathrm{MDA}$, and the expression of NADPH in the brain of diabetic rats.

In a similar pattern, systemic administration of losartan in diabetic hypertensive rats significantly reduced the expression of inducible nitric oxide synthase (iNOS) and reestablished the antioxidant system (Silva et al., 2010). Evidences suggested that activation of iNOS causes DNA breaks with a subsequent activation of poly (ADP-ribose) polymerase (PARP) which is an important regulator of several pro-inflammatory mediators. It also has the ability to increase the leukocytes adhesion to the endothelial cells, as well as to enhance the formation of vascular endothelial growth factor (Silva et al., 2010; Zakaria et al., 2016).

Several studies demonstrated the ability of the ARBs to exert their cardiovascular protective actions through other mechanisms which are not just blockade of AngII signaling. Thomas et al. (2013) reported that valsartan treatment partially suppressed the elevated inflammatory cytokines, namely, TNF $\alpha$, IL- $1 \beta$, IFN $\gamma$, and MCP-1in STZ diabetic mice.

Similarly, valsartan through the activation of AMP-activated protein kinase succeeded in inhibiting the expression of early growth response factor 1 (Egr-1) in the aorta of STZ-induced diabetic mice. This response significantly resulted 
in inhibiting the expression of the inflammatory cytokines, TLR-2 and TLR-4. Egr-1 is a nuclear protein that has been reported to act as a major contributor in the pathogenesis of atherosclerosis by inducing the formation of foam cells, with subsequent thrombosis and restenosis (Ha et al., 2014).

In the current study, the histopathological examination of aortic sections from the valsartan and losartan treated diabetic rats at the high dose levels revealed regaining of the normal architecture of the aortic wall. These data were consistent with the results of Tikellis et al. (2013) who reported that blockade of the RAAS was able to inhibit the diabetes-associated atherosclerotic plaque formation in atherosclerosis-prone apoE KO (apolipoprotein E knockout)-mice, through blood pressure independent mechanism (Kurtz and Pravenec, 2008).

The beneficial effect of losartan administration in suppressing the progression of arterial stiffness when administered in hyperglycemic patients has been documented by Uehara and Takeda (2008). Also, Kurtz and Pravenec (2008) have pointed out the role of losartan and its metabolite EXP3174 in interfering with the platelet aggregation and vasoconstriction induced by a thromboxane receptor agonist, while valsartan appears to have little or no effect. They have discussed the ability of losartan to interfere with the binding of thromboxane A2/prostaglandin endoperoxide $\mathrm{H} 2$ (TxA2/PGH2) ligand to its receptors on platelets or coronary arteries, thereby promoting further protection against coronary events in a mechanism which is not just depend on AT1 receptor blockade.

The current results demonstrated that daily administration of metformin $(100 \mathrm{mg} / \mathrm{kg})$ to the $\mathrm{STZ}$ diabetic rats resulted in a numerical, but non-significant, tendency to decrease the blood pressure with no effect on heart rate.

However, Majithiya and Balaraman (2006) showed that administration of metformin resulted in a significant decrease in SBP.

Metformin is a biguanide oral antidiabetic agent used for the control of type 2 diabetes. Its hypoglycemic actions are mainly mediated through inhibition of gluconeogenesis, enhancement of hepatic insulin sensitivity, as well as stimulation of glucose uptake in skeletal muscle and adipocytes. Several authors have discussed the benefits of metformin in reducing the cardiovascular-related mortality rates in type 2 diabetic patients (Alhaider et al., 2011; Ouslimani et al., 2005; Rahimi et al., 2005).

Majithiya and Balaraman (2006) discussed the beneficial effects of metformin in improving the vascular function in diabetic rats against the STZ- induced vasculopathy. They reported the ability of metformin to increase the activity of NO without affecting its expression. This effect was mediated through inhibiting the breakdown of NO by the activated ROS.

In the present piece of work, the daily metformin administration resulted in a significant decrease in the level of MDA associated with numerical non-significant increase in the blood GSH content when compared with the STZ diabetic untreated rats. In addition, the histopathological examination of the aortic sections from the metformin treated rats revealed almost regaining the normal architecture of the aortic wall.

The antioxidant properties of metformin have been documented by several authors (Sabry et al., 2014; Singh et al., 2016; Soon and Tan, 2002). They documented the upregulation of the antioxidant enzymes such as SOD and catalase, as well as the increased GSH concentration in response to the administration of metformin. In addition, Rahimi et al. (2005) and Sabry et al. (2014) reported the ability of metformin to inhibit the generation of ROS by suppressing the activities of NAD(P)H oxidase and/or mitochondrial respiratory chain.

In summary, the present study showed that blockage of AT1 receptors with ARBs (valsartan and losartan) succeeded in ameliorating the cardiovascular hemodynamic abnormalities and the vascular structural aberrations associated with the STZ-induced diabetes. These protective effects could be in part mediated through ameliorating the generation of ROS.

\section{ACKNOWLEDGMENTS}

The authors would like to gratefully acknowledge Mayar Desouki, Clinical Audiology, School of Communication Sciences and Disorders, University of Memphis, USA for editing the English language of this paper.

\section{FINANCIAL SUPPORT AND SPONSORSHIP}

This study is financially supported by National research Center, Cairo, Egypt.

\section{CONFLICT OF INTERESTS}

There are no conflicts of interest.

\section{REFERENCES}

Alhaider AA, Korashy HM, Sayed-Ahmed MM, Mobark M, Kfoury H, Mansour MA. Metformin attenuates streptozotocin-induced diabetic nephropathy in rats through modulation of oxidative stress genes expression. Chem Biol Interact, 2011; 192(3):233-42.

Beutler E, Duron O, Kelly BM. Improved method for the determination of blood glutathione. J Lab Clin Med, 1963; 61:882-8.

Chahlia N. Comparative evaluation of the hypoglycaemic activity of various parts of Capparis decidua. Biharean Biologist, 2009; 3(1):13-7.

Chan P, Wong KL, Liu IM, Tzeng TF, Yang TL, Cheng JT. Antihyperglycemic action of angiotensin II receptor antagonist, valsartan, in streptozotocin-induced diabetic rats. J Hypertens, 2003; 21(4):761-9.

Cocchetto DM, Bjornsson TD. Methods for vascular access and collection of body fluids from the laboratory rat. J Pharm Sci, 1983; 72(5):465-92.

d'Uscio LV, Shaw S, Barton M, Lüscher TF. Losartan but not verapamil inhibits angiotensin II-induced tissue endothelin-1 increase Role Blood Press Endot Func, 1998; 31(6):1305-10.

Drury RAB, Wallington EA. Preparation and fixation of tissues. In: Carleton HM, Drury RAB, Wallington EA (eds.). Carleton's histological technique. 5th edition, Oxford University Press, Oxford; New York, p. 206, 1980.

El-Batran SA, Abdel-Salam OM, Nofal SM, Baiuomy AR. Effect of rosiglitazone and nateglinide on serum glucose and lipid profile alone or in combination with the biguanide metformin in diabetic rats. Pharmacol Res, 2006; 53(1):69-74.

El-Mosallamy AEMK, Sleem AA, Abdel-Salam OME, Shaffie N, Kenawy SA. Antihypertensive and cardioprotective effects of pumpkin seed oil. J Med Food, 2012; 15(2):180-9.

El-Shenawy SM, Sleem AA, Salama SH. Hypolipidemic activity of losartan and valsartan in experimentally induced hyperlipidemia in male albino rats. J Egypt Soc Pharmacol Exp Therap, 2004; 25(2):361-73.

Esper R, Vilariño J, Machado R, Paragano A. Endothelial dysfunction in normal and abnormal glucose metabolism. In: Cardiovascular diabetology: clinical, metabolic and inflammatory facets (ed.). Karger Publishers, pp. 17-43, 2008. 
Fang ZY, Prins JB, Marwick TH. Diabetic cardiomyopathy: evidence, mechanisms, and therapeutic implications. Endocr Rev, 2004; 25(4):543-67.

Fiorino P, Evangelista FSA, Santos F, Magri FMM, Delorenzi JCMO, Ginoza M, Farah V. The effects of green tea consumption on cardiometabolic alterations induced by experimental diabetes. Exp Diabetes Res, 2012; 2012:309231.

Fregly MJ. Effect of chlorothiazide and hydrochlorothiazide on blood pressure and thyroid activity of hypertensive rats. Am J Cardiol, $1961 ; 8: 890-8$.

Fujita H, Sakamoto T, Komatsu K, Fujishima H, Morii T, Narita T, Takahashi T, Yamada Y. Reduction of circulating superoxide dismutase activity in type 2 diabetic patients with microalbuminuria and its modulation by telmisartan therapy. Hypertens Res, 2011; 34(12):1302-8.

Fukui S, Fukumoto Y, Suzuki J, Saji K, Nawata J, Shinozaki T, Kagaya Y, Watanabe J, Shimokawa H. Diabetes mellitus accelerates left ventricular diastolic dysfunction through activation of the renin-angiotensin system in hypertensive rats. Hypertens Res, 2009; 32(6):472-80.

Goyal BR, Solanki N, Goyal RK, Mehta AA. Investigation into the cardiac effects of spironolactone in the experimental model of type 1 diabetes. J Cardiovasc Pharmacol, 2009; 54(6):502-9.

Grise KN, Olver TD, McDonald MW, Dey A, Jiang M, Lacefield JC, Shoemaker JK, Noble EG, Melling CW. High intensity aerobic exercise training improves deficits of cardiovascular autonomic function in a rat model of type 1 diabetes mellitus with moderate hyperglycemia. J Diabetes Res, 2016; 2016:8164518.

Gupta D, Griendling KK, Taylor WR. Oxidative stress and cardiovascular disease in diabetes mellitus. In: Sauer H, Shah AM, Laurindo FRM (eds.). Studies on cardiovascular disorders.Humana Press, Totowa, NJ, pp. 263-79, 2010.

Ha YM, Park EJ, Kang YJ, Park SW, Kim HJ, Chang KC. Valsartan independent of AT1 receptor inhibits tissue factor, TLR-2 and -4 expression by regulation of Egr-1 through activation of AMPK in diabetic conditions. J Cell Mol Med, 2014; 18(10):2031-43.

Haidara MA, Mikhailidis DP, Rateb MA, Ahmed ZA, Yassin HZ, Ibrahim IM, Rashed LA. Evaluation of the effect of oxidative stress and vitamin E supplementation on renal function in rats with streptozotocininduced Type 1 diabetes. J Diabetes Complicat, 2009; 23(2):130-6.

Hansen PS, Clarke RJ, Buhagiar KA, Hamilton E, Garcia A, White C, Rasmussen HH. Alloxan-induced diabetes reduces sarcolemmal $\mathrm{Na}+-\mathrm{K}+$ pump function in rabbit ventricular myocytes. Amer J Physiol Cell Physiol, 2007; 292(3):C1070-7.

Hassan N, El-Bassossy HM, Zakaria MNM. Heme oxygenase-1 induction protects against hypertension associated with diabetes: effect on exaggerated vascular contractility. Naunyn Schmiedeberg's Arch Pharmacol, 2013; 386(3):217-26.

Howarth FC, Jacobson M, Naseer O, Adeghate E. Short-term effects of streptozotocin-induced diabetes on the electrocardiogram, physical activity and body temperature in rats. Exp Physiol, 2005; 90(2):237-45.

Hussien AASNI. Cardiac apoptosis as a possible cause of diabetic cardiomyopathy and the protective role of alpha lipoic acid and Losartan in diabetic rats. Int J, 2014; 2(11):325-37.

IDF. Diabetes: A global emergency. In: Cavan D, Fernandes JdR, Makaroff L, Ogurtsova K, Webber S (eds.). IDF diabetes atlas seventh edition, pp. 12-13, 2015.

Irvine RJ, White J, Chan R. The influence of restraint on blood pressure in the rat. J Pharmacol Toxicol Methods, 1997; 38(3):157-62.

Islam M, Loots DT. Diabetes, metallothionein, and zinc interactions: a review. Biofactors, 2007; 29(4):203-12.

Kellogg A. Effect of cyclooxygenase (COX)-2 activation on diabetic neuropathy. University of Toledo, Toledo, OH, 2008.

Koka V, Wang W, Huang XR, Kim-Mitsuyama S, Truong LD, Lan HY. Advanced glycation end products activate a chymase-dependent angiotensin II-generating ppathway in diabetic complications. Circulation, 2006; 113(10):1353-60.
Krejpcio Z, Wojciak R, Krol E. The effect of hyperglycemia on zinc, copper and chromium status in STZ-induced diabetic rats. Trace Elements Electrolyt, 2011; 28(3):156-61.

Kucharewicz I, Pawlak R, Matys T, Pawlak D, Buczko W. Antithrombotic effect of captopril and losartan is mediated by angiotensin-(1-7). Hypertension, 2002; 40(5):774-9.

Kurtz TW, Pravenec M. Molecule-specific effects of angiotensin II-receptor blockers independent of the renin-angiotensin system. Am J Hypertens, 2008; 21(8):852-9.

Lo Giudice P, Careddu A, Magni G, Quagliata T, Pacifici L, Carminati P. Autonomic neuropathy in streptozotocin diabetic rats: effect of acetyl-L-carnitine. Diabetes Res Clin Prac, 2002; 56(3):173-80.

Majithiya JB, Balaraman R. Metformin reduces blood pressure and restores endothelial function in aorta of streptozotocin-induced diabetic rats. Life Sci, 2006; 78(22):2615-24.

Malfitano C, De Angelis K, Fernandes T, Wichi RB, Rosa K, Pazzine M, et al. Low-dose enalapril reduces angiotensin II and attenuates diabetic-induced cardiac and autonomic dysfunctions. J Cardiovasc Pharmacol, 2012; 59(1):58-65.

Marquie G, El Madani T, Solera ML, Pieraggi MT, Hadjiisky P, Ravel D, Seguin L, Bennani N. Metabolic and anti-atherogenic effects of long-term benfluorex in dyslipidemic insulin-resistant sand rats (Psammomys obesus). Life Sci, 1998; 63(1):65-76.

Matsumoto T, Lopes RA, Taguchi K, Kobayashi T, Tostes RC. Linking the beneficial effects of current therapeutic approaches in diabetes to the vascular endothelin system. Life Sci, 2014; 118(2):129-35.

Meamar M, Dehpour T, Mazloom R, Sharifi F, Raoufy MR, Dehpour AR, Mani AR. The effect of endotoxin on heart rate dynamics in diabetic rats. Auton Neurosci, 2015; 189:83-6.

Mihailovic M, Arambasic capital Je SJ, Uskokovic A, Grdovic N, Dinic S, Vidovic S, Poznanović G, Mujić I, Vidaković M. Protective effects of the mushroom lactarius deterrimus extract on systemic oxidative stress and pancreatic islets in streptozotocin-induced diabetic rats. J Diabetes Res, 2015; 2015:576726.

Mihara M, Uchiyama M. Determination of malonaldehyde precursor in tissues by thiobarbituric acid test. Anal Biochem, 1978; 86(1):271-8.

Mori F, Hikichi T, Nagaoka T, Takahashi J, Kitaya N, Yoshida A. Inhibitory effect of losartan, an AT1 angiotensin II receptor antagonist, on increased leucocyte entrapment in retinal microcirculation of diabetic rats. Br J Ophthalmol, 2002; 86(10):1172-4.

Musial DC, da Silva Júnior ED, da Silva RM, Miranda-Ferreira R, Lima-Landman MTR, Jurkiewicz A, et al. Increase of angiotensinconverting enzyme activity and peripheral sympathetic dysfunction could contribute to hypertension development in streptozotocin-induced diabetic rats. Diabetes Vasc Dis Res, 2013; 10:498-504.

Nasser M, Clere N, Botelle L, Javellaud J, Oudart N, Faure S, Achard JM. Opposite effects of angiotensins receptors type 2 and type 4 on streptozotocin induced diabetes vascular alterations in mice. Cardiovasc Diabetol, 2014; 13:40.

Nemoto S, Kobayashi T, Taguchi K, Matsumoto T, Kamata K Losartan improves aortic endothelium-dependent relaxation via prolinerich tyrosine kinase 2/Src/Akt pathway in type 2 diabetic Goto-Kakizaki rats. Am J Physiol Heart Circ Physiol, 2011; 301(6):H2383-94.

Orhan N, Berkkan A, Deliorman Orhan D, Aslan M, Ergun F. Effects of Juniperus oxycedrus ssp. oxycedrus on tissue lipid peroxidation, trace elements $(\mathrm{Cu}, \mathrm{Zn}, \mathrm{Fe})$ and blood glucose levels in experimental diabetes. J Ethnopharmacol, 2011; 133(2):759-64.

Ouslimani N, Peynet J, Bonnefont-Rousselot D, Therond P, Legrand A, Beaudeux JL. Metformin decreases intracellular production of reactive oxygen species in aortic endothelial cells. Metabolism, 2005; 54(6):829-34

Prabhakar SS. Inhibition of renin-angiotensin system: implications for diabetes control and prevention. J Investig Med, 2013; 61(3):551-7. 
Rahimi R, Nikfar S, Larijani B, Abdollahi M. A review on the role of antioxidants in the management of diabetes and its complications. Biomed Pharmacother, 2005; 59(7):365-73.

Riser BL, Cortes P, DeNichilo M, Deshmukh PV, Chahal PS, Mohammed AK, Yee J, Kahkonen D. Urinary CCN2 (CTGF) as a possible predictor of diabetic nephropathy: preliminary report. Kidney Int, 2003; 64(2):451-8.

Sabry MM, Roshdy NK, Rashed LA, ElSebaee HE, Youssef MA, Tawadrous AF. Cross talk between oxidative stress, PPAR-[gamma] and RAS system in diabetic rat heart exposed to ischemia/reperfusion injury. Int J Biochem Res Rev, 2014; 4(1):66-79.

Sampathkumar R, Balasubramanyam M, Rema M, Premanand C, Mohan V. A novel advanced glycation index and its association with diabetes and microangiopathy. Metabolism, 2005; 54(8):1002-7.

Sanyal SN, Wada T, Yamabe M, Anai H, Miyamoto S, Shimada T, Ono K. Synaptic degradation of cardiac autonomic nerves in streptozotocininduced diabetic rats. Pathophysiology, 2012; 19(4):299-307.

Sasaki K, Matsushita S, Sato F, Tokunaga C, Hyodo K, Sakakibara Y. Cardiac sympathetic activity assessed by heart rate variability indicates myocardial ischemia on cold exposure in diabetes. Ann Vasc Dis, 2013; 6(3):583-9.

Senapaty S, Rath B, Jena J, Biswal SB. Comparative effect of angiotensin II type I receptor blocker on blood glucose concentration and oxidative stress in streptozotocin-induced diabetic rats. Int J Pharm Pharm Sci, 2014; 6(6):266-9.

Silva KC, Rosales MA, de Faria JB, de Faria JM. Reduction of inducible nitric oxide synthase via angiotensin receptor blocker prevents the oxidative retinal damage in diabetic hypertensive rats. Curr Eye Res, 2010; 35(6):519-28.

Singh BK, Singh A, Kumar V. Ameliorative effect of adjunct therapy of metformin with atorvastatin on streptozotocin-induced diabetes mellitus in rats. Drug Res (Stuttg), 2016; 66(1):28-32.

Singh K, Singh T, Sharma P. Beneficial effects of angiotensin (17) in diabetic rats with cardiomyopathy. Therap Adv Cardiovasc Dis, 2011; 5(3):159-67.

Soon YY, Tan BK. Evaluation of the hypoglycemic and antioxidant activities of Morinda officinalis in streptozotocin-induced diabetic rats. Singapore Med J, 2002; 43(2):77-85.

Thomas CM, Yong QC, Seqqat R, Chandel N, Feldman DL, Baker KM, Kumar R. Direct renin inhibition prevents cardiac dysfunction in a diabetic mouse model: comparison with an angiotensin receptor antagonist and angiotensin-converting enzyme inhibitor. Clin Sci, 2013; 124(8):529-45.

Thompson K, Godin D. Micronutrients and antioxidants in the progression of diabetes. Nutr Res, 1995; 15(9):1377-410.
Tikellis C, Pickering Raelene J, Tsorotes D, Harjutsalo V, Thorn L, Ahola A, Wadén J, Tolonen N, Saraheimo M, Gordin D, Forsblom C. Association of dietary sodium intake with atherogenesis in experimental diabetes and with cardiovascular disease in patients with Type 1 diabetes. Clin Sci, 2013; 124(10):617-26.

Uehara G, Takeda H. Relative effects of telmisartan, candesartan and losartan on alleviating arterial stiffness in patients with hypertension complicated by diabetes mellitus: an evaluation using the cardio-ankle vascular index (CAVI). J Int Med Res, 2008; 36(5):1094-102.

VanHoose LD. Cardiac dysfunction in the ZDF rat: Possible mechanisms and benefits of exercise. University of Kansas, Kansas, USA, pp. 1-28, 2011.

Wang YC, Chang CT, Tsu PS, Yeh CH, Chiu W-C. Reduction in advanced glycation end products by ACE inhibitor in diabetic cardiomyopathy model. Asian Biomed, 2013; 7(1):29-37.

Xu H, Liu C, Rao S, He L, Zhang T, Sun S, Wu B, Zou L, Wang S, Xue Y, Jia T. LncRNA NONRATT021972 siRNA rescued decreased heart rate variability in diabetic rats in superior cervical ganglia. Autonomic Neurosci, 2016; 201:1-7.

Yang B. Assessment of cardiac autonomic neuropathy (CAN) in type I diabetic mice. Worcester Polytechnic Institute, Worcester, MA, pp. $11-20,2011$

Yavuz D, Kucukkaya B, Haklar G, Ersoz O, Akoglu E, Akalin S. Effects of captopril and losartan on lipid peroxidation, protein oxidation and nitric oxide release in diabetic rat kidney. Prostaglandins Leukotrienes Essential Fatty Acids, 2003; 69(4):223-7.

Zakaria EM, El-Bassossy HM, El-Maraghy NN, Ahmed AF, Ali AA. PARP-1 inhibition alleviates diabetic cardiac complications in experimental animals. Eur J Pharmacol, 2016; 791:444-54.

Zhang C-H, Lu J, Yu X-J, Sun L, Zang W-J. Ameliorative effect of captopril and valsartan on an animal model of diabetic cardiomyopathy. Biol Pharm Bull, 2008; 31(11):2045-2049.

Zhao T-T, Liu X-P, Chen B. Effect of Valsartan on oxidative stress in brain tissue of diabetic rats. J Clin Neurol, 2007; 4:022

\section{How to cite this article:}

El-Mosallamy AEMK, Zaki HF, Shaffie N, Nada SA, Sleem AA, Kenawy SA. Vascular protective actions of the angiotensin receptor blockers valsartan and losartan in STZinduced diabetic rats. J Appl Pharm Sci, 2019; 9(04):066-076. 